\title{
CONJUGATION REACTIONS INVOLVING MALEIMIDES AND PHOSPHOROTHIOATE OLIGONUCLEOTIDES
}

\author{
Albert Sánchez, Enrique Pedroso and Anna Grandas* \\ Departament de Química Orgànica and IBUB, Facultat de Química, Universitat de Barcelona; \\ Martí i Franquès 1-11, 08028 Barcelona, Spain \\ Phone: +34934021263 \\ Fax: +34933397878 \\ e-mail: anna.grandas@ub.edu
}




\begin{abstract}
Phosphorothioate diester oligonucleotides proved to be fully compatible with maleimides in the context of two different conjugation reactions: a) reaction of ${ }^{5}$ diene-[phosphorothioate oligonucleotides] with maleimido-containing compounds to afford the Diels-Alder cycloadduct, b) conjugation of ${ }^{5}$ maleimido-[phosphorothioate oligonucleotides] with thiol-containing compounds. No evidence of reaction between phosphorothioate diesters and maleimides was found in any of these processes. Importantly, in the preparation of ${ }^{5}$ maleimido-[phosphorothioate oligonucleotides] from [protected maleimido]-[phosphorothioate oligonucleotides], which requires the maleimide to be deprotected by retro-Diels-Alder reaction (heating for 3-4 $\mathrm{h}$ in toluene at $90{ }^{\circ} \mathrm{C}$ ), no addition of phosphorothioate diester to the maleimide was found either. Finally, maleimide-[phosphorothioate monoester] conjugation was also explored for comparison purposes.
\end{abstract}

\title{
INTRODUCTION
}

Replacement of one of the nonbridging phosphate oxygens with sulfur was among the first modifications of the oligonucleotide backbone shown to down-regulate gene expression, ${ }^{1}$ and the nucleic acid drugs approved so far (Vitravene ${ }^{\mathrm{TM}}$ and Macugen $\left.{ }^{\circledR}\right)$ have internucleoside phosphorothioate linkages.

Phosphorothioate-modified oligonucleotides (PS-ONs) have increased stability to nucleases, and direct RNase H-mediated degradation of RNA in hybrid duplexes. Thiophosphate internucleoside linkages are more lipophilic than the natural phosphate diesters, but they do not significantly improve cell uptake. Hence, special formulations or covalent attachment to other molecules (that is, derivatization as conjugates) are often required to facilitate transport across cell membranes. Sulfur nucleophilicity was early exploited for the preparation of oligonucleotide conjugates. ${ }^{2}$ Thiols were reacted with electrophiles such as bromo- or iodoacetyl groups, with maleimide Michael acceptors, and with other thiols to form disulfides. Thiophosphates were also used as nucleophiles in some of these reactions, but literature information as to their compatibility with other functional groups is somehow contradictory. It has been said, probably stating a fairly 
general feeling, that thiol-maleimide conjugation is not compatible with PS-ONs. ${ }^{3}$ However, data not supporting this feeling have also been made available.

Phosphorothioate diesters have been described to react with activated disulfides such as the Ellman reagent, ${ }^{4}$ most likely forming mixed thiol-thiophosphate disulfides. ${ }^{5}$ Yet, phosphorothioate diesters have also been reported not to react with pyridyldisulfide groups. ${ }^{6}$ In fact, there are various reports on the synthesis of disulfide-linked conjugates of phosphorothioated oligonucleotides, ${ }^{7-9}$ showing that disulfides between two thiols can be formed in the presence and with no interference of phosphorothioate groups.

Thiophosphates, either mono- or diesters, are known to react with bromo- or iodoacetyl groups, ${ }^{10,11}$ and this was reported to be the preferred reaction when PS-ONs and bifunctional linkers containing maleimide and haloacetyl groups were mixed. ${ }^{12}$

Phosphorothioate monoesters and the $\omega$-thiophosphate of nucleoside di- and triphosphates react with maleimides, ${ }^{13-17}$ giving the corresponding Michael-type adduct. The Michael addition has been described to be more difficult in the case of thiophosphate diesters, especially in comparison with the thiol-maleimide reaction, but to take place to a non-negligible extent. In this respect, it is worth noting that the thiol-maleimide Michael-type addition has been described to occur when maleimido-[PS-ONs] react with thiol-containing compounds, as well as when thiol-derivatized PS-ONs react with maleimide-containing compounds. ${ }^{18-20}$

The interest in modified oligonucleotides and conjugates does not cease to increase, because so are doing their applications in the bio-pharmaceutical and nanotechnological fields (gene silencing studies, use of oligonucleotides to suppress immune responses, immobilization of oligonucleotides for the preparation of microarrays and biosensors, etc.). ${ }^{21-26}$ Introduction of phosphorothioate linkages is a common, useful modification of oligonucleotide chains, so it is important to assess under what circumstances PS-ONs can be reliably used.

In this work we wish to describe that reaction between diene-derivatized PS-ONs and maleimides gives the Diels-Alder cycloadduct, showing that phosphorothioate diesters do not interfere with this reaction. We also applied the methodology that allows maleimido-oligonucleotides to be onresin assembled ${ }^{27}$ to the synthesis of maleimide-[PS-ONs], which proved that in the heating process required to obtain maleimido-[PS-ONs] from [protected-maleimido]-[PS-ONs] there is no addition of the thiophosphate diester to the maleimide. Furthermore, and as expected, reaction between these maleimido-[PS-ONs] and thiol-containing compounds provided the target 
conjugates. Finally, maleimide-[phosphorothioate monoester] conjugation was also explored for comparison purposes.

\section{MATERIALS AND METHODS}

Nucleoside phosphoramidites, DMT-O- $\mathrm{CH}_{2} \mathrm{CH}_{2}-\mathrm{SO}_{2}-\mathrm{CH}_{2} \mathrm{CH}_{2}-\mathrm{O}-\mathrm{P}(\mathrm{OCNE}) \mathrm{N}^{i} \mathrm{Pr}_{2}$ and CPG supports were from either Link Technologies or Glen Research Corporation. Oligonucleotide chains were elongated in a $3400 \mathrm{ABI}$ automatic synthesizer at the $1 \mu \mathrm{mol}$ scale, using standard phosphite triester approach synthesis cycles and the phosphoramidite derivatives of $\mathrm{dA}^{\mathrm{Pac}}, \mathrm{dC}^{\mathrm{Ac}}$, $\mathrm{dG}^{\mathrm{iPrPac}}$ and $\mathrm{dT}$ (Pac=phenoxyacetyl, iPrPac=(4-isopropyl-phenoxy)acetyl). Sulfurization of phosphite triesters was carried out with the Beaucage reagent. ${ }^{28}$ Maleimido-biotin derivative 4a was from Thermo Scientific (EZ-Link ${ }^{\circledR}$ Maleimide-PEG ${ }_{2}$-Biotin). D-(+) Biotin $N$-hydroxysuccinimide ester (biotin-OSu) was from Berry \& Associates. Dienephosphoramidite (see Scheme 1) was synthesized as described by Hill et al. ${ }^{29}$ Syntheses of [protected maleimide]-phosphoramidite (see Scheme 2) and H-Cys-Lys-Glu-Thr-Ala-Ala-AlaLys-Phe-Glu-Arg-Gln-His-Met-Asp-Ser-Ser-Thr-Ser-Ala-Ala-OH (Cys-peptide, 8b) are described in reference 27. Preparation of maleimido-Lys-Glu-Thr-Ala-Ala-Ala-Lys-Phe-GluArg-Gln-His-Met-Asp-Ser-Ser-Thr-Ser-Ala-Ala-OH (Mal-peptide, $\mathbf{4 b}$ ) is described in reference 30.

TLC was carried out on silica gel plates $60 \mathrm{~F}_{254}$ from Merck.

Reversed-phase HPLC analysis and purification was performed using analytical and semipreparative Waters systems. Unless otherwise indicated, a Kromasil C18 column (10 $\mu \mathrm{m}$, $100 \AA$ A, $250 \times 4.0 \mathrm{~mm}$ ) from Akzo Nobel, solvent A: $0.05 \mathrm{M}$ triethylammonium acetate, solvent B: $\mathrm{H}_{2} \mathrm{O} /$ acetonitrile $(1: 1, \mathrm{v} / \mathrm{v})$, flow: $1 \mathrm{~mL} / \mathrm{min}$, detection wavelength: $254 \mathrm{~nm}$, and linear gradients from 10 to $80 \%$ of B in 30 min were used in analytical HPLC. Semipreparative conditions: Jupiter C18 column $(10 \mu \mathrm{m}, 300 \AA, 250 \times 10.0 \mathrm{~mm})$ from Phenomenex, solvent A: $0.1 \mathrm{M}$ triethylammonium acetate, solvent $\mathrm{B}: \mathrm{H}_{2} \mathrm{O} /$ acetonitrile $(1: 1)(\mathrm{v} / \mathrm{v})$, flow: $3 \mathrm{~mL} / \mathrm{min}$, detection wavelength: $260 \mathrm{~nm}$, linear gradient from 10 to $80 \%$ of B in $30 \mathrm{~min}$.

MALDI-TOF mass spectra were recorded on a 4800 Plus ABSciex instrument. Typical analysis conditions: 1:1 (v/v) 2,4,6-trihydroxyacetophenone/ammonium citrate (THAP/CA) in the negative mode (3-hydroxypicolinic acid, HPA, was used instead of THAP in some cases); 2,5- 
dihydroxybenzoic acid $+0.1 \%$ trifluoroacetic acid in the positive mode; unless otherwise indicated, spectra were recorded in the negative mode and reflector was used. ESI mass spectra were obtained using an LC/MSD-TOF Agilent technologies spectrometer from Agilent Technologies.

\section{Diene-[phosphorothioate oligonucleotides] (3).}

Resin-linked phosphorothioate oligonucleotides 2 were assembled using standard procedures (phosphite triester approach), and the same chemistry was used to incorporate the diene moiety at the $5^{\prime}$ end. ${ }^{31}$ A $0.05 \mathrm{M}$ solution of the Beaucage reagent in anh. acetonitrile was used for the sulfurization step. To optimize the coupling yield, diene-phosphoramidite was incorporated using a double 5 min-coupling. Deprotection and cleavage was carried out by reaction with concd. aqueous ammonia at room temperature $(4 \mathrm{~h})$. Pure diene-oligonucleotides 3 were obtained after purification by HPLC (Figure S3).

Diene- $^{5}\left[\mathrm{PS}-\mathrm{dT}_{10}\right]$ (3a): $\mathrm{t}_{\mathrm{R}}=16.4 \mathrm{~min}$; MALDI-TOF MS: m/z 3297.7 [M-H] $]^{-}$, M calcd. 3298.7. Diene- ${ }^{-}$[PS-dTCTCCCAGCGTGCGCCAT] (3b): $\mathrm{t}_{\mathrm{R}}=14.7 \mathrm{~min}$; MALDI-TOF MS (linear): $\mathrm{m} / \mathrm{z}$ 5850.4, M calcd. 5856.5.

\section{Synthesis of conjugates (5) by Diels-Alder cycloaddition.}

Maleimide-containing compounds can be quantified by measuring the absorbance at $299 \mathrm{~nm}$ (in water, $\left.\varepsilon_{299}=551.46 \mathrm{M}^{-1} \mathrm{~cm}^{-1}\right)$.

Maleimide-containing compound 4 (2 equiv) was added to diene-[PS-ON] 3 ( $\left.2 \mathrm{OD}_{260}\right)$, and the mixture was heated in a metal block for $15 \mathrm{~h}$ at $37^{\circ} \mathrm{C}$ (concentration of $\mathbf{3}$ in the conjugation reaction mixture: $50 \mu \mathrm{M}$; solvent: water). The reactions with $\mathbf{4 a}$ did not go to completion (as shown by HPLC analysis: Figure 2), so an additional amount of $\mathbf{4 a}$ was added (10 equiv) and the reaction pursued overnight. Pure conjugates $\mathbf{5}$ were obtained after purification by HPLC. Their identity was confirmed by MALDI-TOF MS.

Biotin- $^{5}\left[\mathrm{PS}-\mathrm{dT}_{10}\right]: \mathrm{t}_{\mathrm{R}}=15.6 \mathrm{~min}$; MALDI-TOF MS: $m / z$ z 3822.6 [M-H] ${ }^{-}$, M calcd. 3823.5 . Biotin- $^{5}$ [PS-dTCTCCCAGCGTGCGCCAT]: $\mathrm{t}_{\mathrm{R}}=14.4 \mathrm{~min} ;$ MALDI-TOF MS (linear): $\mathrm{m} / z$ 6375.7 [M-H] ${ }^{-}, \mathrm{M}$ calcd. 6381.8. 
Peptide- ${ }^{5}\left[\mathrm{PS}-\mathrm{dT}_{10}\right]: \mathrm{t}_{\mathrm{R}}=14.4 \mathrm{~min} ; \mathrm{m} / \mathrm{z}$ 5613.4 [M-H] $]^{-}, \mathrm{M}$ calcd. 5614.4.

Peptide-- ${ }^{5}$ [PS-dTCTCCCAGCGTGCGCCAT]: $\mathrm{t}_{\mathrm{R}}=13.2 \mathrm{~min} ;$ MALDI-TOF MS (linear): $\mathrm{m} / \mathrm{z}$ 8166.2 [M-H] $]^{-}, \mathrm{M}$ calcd. 8172.6.

\section{[Protected maleimido]-[phosphorothioate-oligonucleotides] (6).}

Resin-linked phosphorothioate oligonucleotides 2 were assembled using standard procedures (phosphite triester approach), and the same chemistry was used to incorporate the protected maleimide moiety at the 5' end. A $0.05 \mathrm{M}$ solution of the Beaucage reagent in anh. acetonitrile was used for the sulfurization step. To optimize the coupling yield, [protected maleimido]phosphoramidite was incorporated using a double 5 min-coupling. Deprotection and cleavage was carried out by reaction with concd. aqueous ammonia at room temperature ( $4 \mathrm{~h})$. Pure [protected maleimido]-oligonucleotides 6 were obtained after purification by HPLC (Figure S5). As stated before, ${ }^{27}$ peaks with $\mathrm{m} / \mathrm{z}$ ratios corresponding to both [protected maleimido]-[PS-ON] and maleimido-[PS-ON] were observed upon recording MALDI-TOF MS spectra. Analysis using softer ionization techniques (ESI, data not shown) confirmed that the target [protected maleimido]-[PS-ON] had been obtained.

[Protected maleimido]- ${ }^{5}\left[\mathrm{PS}-\mathrm{dT}_{10}\right](\mathbf{6 a}): \mathrm{t}_{\mathrm{R}}=13.9 \mathrm{~min}$; MALDI-TOF MS: m/z 3436.5 [M-H] ${ }^{-}, \mathrm{M}$ calcd. 3537.3.

[Protected maleimido]- ${ }^{5}$ [PS-dTCTCCCAGCGTGCGCCAT] $(\mathbf{6 b}): \mathrm{t}_{\mathrm{R}}=14.0 \mathrm{~min}$; MALDI-TOF MS (HPA/CA): m/z 5994.6 [M-H]', M calcd. 5995.6.

\section{Maleimido-oligonucleotides (7).}

The maleimide moiety of [protected maleimido]-oligonucleotides $\mathbf{6}$ was deprotected by heating in toluene: A solution of $\mathbf{6}$ was introduced in a vial and evaporated to dryness under vacuum. The resulting residue was dried by coevaporation with toluene $(3 \times)$, and toluene was added (the amount that would be required to obtain a $25 \mu \mathrm{M}$ solution were the oligonucleotide soluble in toluene). This mixture was heated in a metal heating block for $3 \mathrm{~h}$, after which time toluene was removed under reduced pressure. The resulting crude was dissolved in water and analyzed by HPLC (Figure 3). Maleimido-[PS-ONs] 7 were used in conjugation reactions immediately after deprotection. 
Maleimido-- ${ }^{5}\left[\mathrm{PS}-\mathrm{dT}_{10}\right](\mathbf{7 a}): \mathrm{t}_{\mathrm{R}}=12.5 \mathrm{~min} ; \mathrm{MALDI}-\mathrm{TOF}$ MS: $m / z 3340.5[\mathrm{M}-\mathrm{H}]^{-}, \mathrm{M}$ calcd. 3341.3.

Maleimido- ${ }^{5}$ [PS-dTCTCCCAGCGTGCGCCAT] (7b): $\mathrm{t}_{\mathrm{R}}=13.0 \mathrm{~min}$; MALDI-TOF MS (linear, HPA/CA): $m / z, 5894.5$ [M-H]', M calcd. 5899.5.

\section{Synthesis of conjugates (9) by thiol addition to maleimides.}

Quantification of free thiols in thiol-containing compounds was carried out using the Ellman test. $^{32}$

The conjugation reaction was carried out at room temperature in the following conditions: 0.05 $\mathrm{M}$ triethylammonium acetate, $\mathrm{pH}=7.8$; concentration of $\mathbf{7}$ in the conjugation reaction mixture: 25 $\mu \mathrm{M}$; 1:10 maleimido-[PS-ON]/thiol molar ratio; reaction time: $15 \mathrm{~h}$. The required amounts of each of the reagents were mixed, the mixture was diluted with the conjugation buffer, and the $\mathrm{pH}$ adjusted to 7.8. Conjugation crudes were analyzed by HPLC (Figure 4), which showed that the conjugation yield was virtually quantitative. Pure conjugates 9 (identity assessed by MALDITOF MS) were obtained after purification by HPLC.

Biotin- ${ }^{5}\left[\mathrm{PS}-\mathrm{dT}_{10}\right]: \mathrm{t}_{\mathrm{R}}=15.2 \mathrm{~min}$; MALDI-TOF MS: $m / z$ 3643.5 [M-H] ${ }^{-}$, M calcd. 3644.4. Biotin- $^{5}$ [PS-dTCTCCCAGCGTGCGCCAT]: $\mathrm{t}_{\mathrm{R}}=13.8 \mathrm{~min}$; MALDI-TOF MS: $m / z$ 6201.8 [M$\mathrm{H}^{-}, \mathrm{M}$ calcd. 6202.6 .

Peptide-- ${ }^{5}\left[\mathrm{PS}-\mathrm{dT}_{10}\right]: \mathrm{t}_{\mathrm{R}}=14.0 \mathrm{~min}$; MALDI-TOF MS (HPA/CA): $m / z 5608.6[\mathrm{M}-\mathrm{H}]^{-}, \mathrm{M}$ calcd. 5609.3 .

Peptide- ${ }^{5}$ [PS-dTCTCCCAGCGTGCGCCAT]: $\mathrm{t}_{\mathrm{R}}=12.9 \mathrm{~min} ;$ MALDI-TOF MS (linear, HPA/CA): $m / z$ 8163.1 [M-H]', M calcd. 8167.5.

\section{5'-Thiophosphate-dT $10(10)$.}

The oligonucleotide chain was assembled using the standard phosphite triester methodology, which was also used to thiophosphorylate the $5^{\prime}$ end (incorporation of DMT-O- $\mathrm{CH}_{2} \mathrm{CH}_{2}-\mathrm{SO}_{2}$ $\mathrm{CH}_{2} \mathrm{CH}_{2}-\mathrm{O}-\mathrm{P}(\mathrm{OCNE}) \mathrm{N}^{\mathrm{i}} \mathrm{Pr}_{2}$ was followed by sulfurization using the Beaucage reagent). DMT-O$\mathrm{CH}_{2} \mathrm{CH}_{2}-\mathrm{SO}_{2}-\mathrm{CH}_{2} \mathrm{CH}_{2}-\mathrm{O}-\mathrm{P}(\mathrm{O})(\mathrm{OCNE})-{ }^{5} \mathrm{O}$-[protected $\left.\mathrm{dT}_{10}\right]$-resin was treated with concd. aqueous ammonia $(500 \mu \mathrm{L})$ overnight at $60{ }^{\circ} \mathrm{C}$, and the resulting crude was analyzed by HPLC 
(Figure S6a) and MALDI-TOF MS. Purification by semi-preparative HPLC did not provide pure $\mathbf{1 0}$ (Figure S6b), but the mixture of $\mathbf{1 0}$ and dephosphorylated $\mathrm{dT}_{10}$ that was used in the conjugation reactions.

$\mathrm{P}(\mathrm{S})\left(\mathrm{O}^{-}\right)\left(\mathrm{O}^{-}\right)-{ }^{5^{\prime}} \mathrm{dT}_{10}(\mathbf{1 0}): \mathrm{t}_{\mathrm{R}}=20.5 \mathrm{~min} ; \mathrm{MALDI}-\mathrm{TOF} \mathrm{MS}: \mathrm{m} / z, 3073.6[\mathrm{M}-\mathrm{H}]^{-}, \mathrm{M}$ calcd. 3074.5 . $\mathrm{dT}_{10:} \mathrm{t}_{\mathrm{R}}:=21.8 \mathrm{~min} ;$ MALDI-TOF MS: m/z 2977.7 [M-H] ${ }^{-}$, M calcd. 2978.5.

\section{Synthesis of conjugates 11 by addition of the thiophosphate monoester to the maleimide.}

$\mathrm{P}(\mathrm{S})\left(\mathrm{O}^{-}\right)\left(\mathrm{O}^{-}\right)-\mathrm{dT}_{10}\left(\mathbf{1 0}, 0.2 \mathrm{OD}_{260}\right.$, plus the $\mathrm{dT}_{10}$ impurity) was dissolved in $0.5 \mathrm{M}$ triethylammonium acetate buffer, $\mathrm{pH}=7.8$ ). 10 equiv (with respect to compound $\mathbf{1 0}, 75 \%$ in the mixture as shown by HPLC - Figure S6b) of maleimido-derivative 4 (the required amount of a $3.86 \mathrm{mM}$ aqueous solution of maleimido-biotin $\mathbf{4 a}$, or of a $2.76 \mathrm{mM}$ aqueous solution of maleimido-peptide $\mathbf{4 b}$ ) was added, as well as buffer so that the final volume was $200 \mu \mathrm{L}$ (concentration of $\mathbf{1 0}$ in the conjugation reaction mixture: $25 \mu \mathrm{M}$ ). The resulting mixture was stirred overnight at room temperature under an Ar atmosphere. The crudes were analyzed by HPLC (gradient from 10 to $40 \%$ of B in 30 min, Figure S6c,d), the different peaks were collected and mass spectrometric analysis allowed the target conjugate (11) to be identified. Pure conjugates 11 were isolated after HPLC purification. Conjugation yields: $\mathrm{P}(\mathrm{S})\left(\mathrm{O}^{-}\right)\left(\mathrm{O}^{-}\right)-\mathrm{dT}_{10}(\mathbf{1 0})$ + HS-biotin (8b) $63 \%, \mathrm{P}(\mathrm{S})\left(\mathrm{O}^{-}\right)\left(\mathrm{O}^{-}\right)-\mathrm{dT}_{10}(\mathbf{1 0})+$ maleimido-peptide (4b) $43 \%$. Biotin-dT ${ }_{10}: \mathrm{t}_{\mathrm{R}}=20.9$ min; MALDI-TOF MS: m/z 3598.6 [M-H]', M calcd. 3599.7 Peptide-dT ${ }_{10}: \mathrm{t}_{\mathrm{R}}:=20.5$ min; MALDI-TOF MS: m/z $5389.5[\mathrm{M}-\mathrm{H}]^{-}, \mathrm{M}$ calcd. 5390.5.

\section{RESULTS AND DISCUSSION}

The first experiments we performed aimed to confirm, in a model system, that maleimides and phosphorothioate diesters are compatible, in other words, that they do not react with each other. These experiments were similar to those previously described in the literature, ${ }^{15}$ and consisted in mixing model compound dT-PS-dT (1, Figure 1) with $N$-methylmaleimide and analyzing the reaction mixture.

Dinucleotide 1 was assembled by standard solid-phase synthesis, the phosphite triester sulfurized by reaction with the Beaucage reagent, and permanent protecting groups removed by reaction 
with concentrated aqueous ammonia. HPLC analysis of the crude showed the presence of two main peaks, both having the mass of the target dinucleotide, which were collected separately (Figure S1). Access to each of the two phosphorothioate diastereomers, 1a and 1b (Figure 1), offered the possibility of assessing whether they might react differently. Mixtures of either thiophosphate isomer and $N$-methylmaleimide (1:10 and 1:100 molar ratios) were left to react overnight at room temperature, under conditions similar to those that we had used in thiol-maleimide conjugations. ${ }^{27}$ Subsequent HPLC (Figure S2) and mass spectrometric analyses showed the presence of only $\mathbf{1 a}$ or $\mathbf{1 b}$ in the corresponding crudes. In other words, no adduct resulting from Michael addition of the thiophosphate to the double bond of the maleimide ring was found, which indicated that no intermolecular maleimide-thiophosphate reaction had taken place. This is in contrast with a literature report stating that phosphorothioate diesters can add to the maleimide double bond, ${ }^{15}$ in which the reaction between $N$-(1-pyrene)maleimide and a hundred-fold excess of either dT-PS-dT or $\beta$-mercaptoethanol was monitored by fluorescence spectroscopy. The authors found the extent of the reaction of the maleimide with the thiophosphate diester to be about $25 \%$ of that with the thiol, which is usually quantitative. Certainly their reaction and especially their analysis conditions were different from ours, but we should have been able to detect formation of the Michael adduct had the reaction between $\mathbf{1}$ and $N$-methylmaleimide taken place even in a lower extent.

As previously stated, different experiments have pointed to thiols being much more reactive than phosphorothioate diesters in Michael-type reactions in which the electrophilic species is a maleimide. Yet, it has not been proved that the Diels-Alder reaction between dienes and maleimides is also compatible with thiophosphate diesters.

Two diene-derivatized PS-ONs (3, Scheme 1) were prepared following described procedures, ${ }^{31}$ with the only difference that all phosphite triesters were sulfurized instead of oxidized (Figure $\mathrm{S} 3$ ). The synthesis of maleimido-peptide $\mathbf{4 b}$ has previously been reported. ${ }^{30}$ Cycloadditions were carried out overnight, in water, at $37^{\circ} \mathrm{C}$. HPLC analysis of the crudes (Figure 2) showed that reactions of diene-oligonucleotides 3 with 2 equiv of maleimido-peptide $4 \mathbf{b}$ had nearly gone to completion (98-99\% yields), whereas in the same conditions the yield of the cycloadditions involving 3 and maleimido-biotin (4a) ranged between 31 and $34 \%$. Very good to excellent conjugation yields (91-99 \%) were obtained using a higher excess of maleimido-biotin 4a (Figure 2 , e and f). This result is in agreement with previous findings in the group, which indicated that 
the Diels-Alder cycloaddition between diene-oligonucleotides and maleimido-peptides or carbohydrates is much faster than with compounds less polar or having low affinity for the oligonucleotide chain. ${ }^{33}$

As shown in Figure 2, HPLC profiles of the reaction crudes were very clean. A single main peak was found in all cases, which suggests formation of a single conjugation compound. This was confirmed by the fact that only the one-to-one conjugate (in other words, the molecule incorporating one oligonucleotide and either one peptide chain or one biotin label) was detected by mass spectrometric analysis of the crude. Should any of the phosphorothioate internucleoside linkages have reacted with the maleimide ring, mixtures of one-to-one conjugates with different retention times could have been obtained, in addition to conjugates with higher masses formed either by various intermolecular Michael reactions or by Michael reactions in addition to the cycloaddition. Since none of these was detected, we definitely conclude that the conjugates have the structure shown in Scheme 1 (5), that is, the compounds resulting from the Diels-Alder cycloaddition.

The subsequent, more demanding experiments, aimed to evaluate whether thiophosphate diesters and a maleimide moiety can be introduced in the same oligonucleotide chain by stepwise solidphase synthesis (Scheme 2). We have recently described that maleimido-oligonucleotides can be on-resin assembled making use of a maleimide protecting group that remains stable to ammonia, ${ }^{27}$ namely the exo isomer of the adduct resulting from reaction of maleimide with 2,5dimethylfuran. Fully protected maleimido-oligonucleotides can be synthesized using standard solid-phase methodology, and subsequent reaction with concd. aqueous ammonia removes permanent protecting groups on the oligonucleotide chain and provides [protected maleimido]oligonucleotides. Then, a retro-Diels-Alder reaction allows the maleimide moiety to be deprotected and affords the target maleimido-oligonucleotides. Therefore, use of this methodology for the preparation of maleimido-[PS-ONs] requires phosphorothioates not to react with the maleimide during the heating process that deprotects it.

Before undertaking the solid-phase synthesis of maleimido-oligonucleotides, mixtures of either diastereomer of dT-PS-dT (1a or 1b) and $N$-methylmaleimide were submitted to the retro-DielsAlder conditions that remove the 2,5-dimethylfuran maleimide protecting group from the maleimide. ${ }^{27}$ Both HPLC (Figure S4) and MALDI-TOF MS analysis of the crudes showed the 
dinucleotide to remain unaltered, indicating that in these retro-Diels-Alder conditions maleimides do not react with phosphorothioates.

For the synthesis of derivative $\mathbf{8 a}$ (Scheme S1), the $N$-hydroxysuccinimido ester of biotin was reacted with cysteamine. ${ }^{34}$ Peptide $\mathbf{8 b}$ was obtained as previously described. ${ }^{27}$

Fully protected maleimido-[PS-ONs] were assembled on CPG, using a [protected-maleimido]phosphoramidite synthon in the last synthesis cycle (Scheme 2) and the Beaucage reagent for the sulfurization of all phosphite triesters. Treatment with concd. aqueous ammonia at room temperature deprotected the oligonucleotide chain, and, after purification, [protected maleimido][PS-ONs] 6 (Figure S5) were suspended in toluene and heated for $3 \mathrm{~h}$ at $90{ }^{\circ} \mathrm{C}$. HPLC analysis (Figure 3) showed the homogeneity of crude maleimido-[PS-ONs] 7 to be similar to that of maleimido-ONs. ${ }^{27}$ Notably, mass spectrometric analysis of the crudes confirmed formation of the target maleimido-oligonucleotides (7), and thus the compatibility between maleimides and phosphorothioate internucleoside linkages under retro-Diels-Alder deprotection conditions. Additional evidence for a reactive maleimide moiety in oligonucleotides 7 was obtained upon conjugation of maleimido-[PS-ONs] 7 with thiols $(\mathbf{8})$, which yielded fairly homogeneous crudes (Figure 4) in which the main peaks were the expected one-to-one conjugates (9, with one oligonucleotide chain and either $\mathbf{8 a}$ or $\mathbf{8 b}$ ), as confirmed by MALDI-TOF MS. As already discussed (synthesis of conjugates $\mathbf{5}$, see above), the possibility that conjugates $\mathbf{9}$ had the structure of mixed disulfides rather than Michael adducts can be ruled out.

Finally, with the aim to compare conjugations involving maleimides and terminal phosphorothioate monoesters (Scheme 3) with Diels-Alder cycloadditions and maleimide-thiol Michael reactions, oligonucleotide 5'-thiophosphate-dT ${ }_{10}(\mathbf{1 0})$ was synthesized, and reacted with $\mathbf{4 a}$ and $\mathbf{4 b}$.

Oligonucleotide 10 was assembled by coupling the 5'-phosphorylating reagent DMT-O- $\mathrm{CH}_{2} \mathrm{CH}_{2}-$ $\mathrm{SO}_{2}-\mathrm{CH}_{2} \mathrm{CH}_{2}-\mathrm{O}-\mathrm{P}(\mathrm{OCNE}) \mathrm{N}^{\mathrm{i}} \mathrm{Pr}_{2}$ to resin-linked $\mathrm{dT}_{10}$, sulfurization and deprotection with ammonia. 10 Was found to undergo dephosphorylation quite easily (Figure S6a,b). ${ }^{35}$ However, since $\mathrm{dT}_{10}$ does not interfere with the conjugation reaction, a mixture of $\mathbf{1 0}$ and $\mathrm{dT}_{10}$ was used in the conjugation reaction with maleimido-compounds 4 . HPLC analysis of the crudes showed that conjugation yields were lower than those of the other conjugation methodologies (Figure S6c,d). Both Diels-Alder and Michael-type conjugation reactions between suitably-derivatized PS-ONs and an excess (2-10 equiv) of the other reagent (maleimide or thiol, respectively) had gone to 
completion after overnight reaction, while unreacted $\mathbf{1 0}$ was still found to be present in the conjugation crude after overnight reaction with 10 equiv of 4 . In any case, the target conjugates (11) were obtained, isolated and characterized, confirming that 5'-thiophosphate oligonucleotides do react with maleimides while phosphorothioate diesters do not.

\section{CONCLUSIONS}

In summary, phosphorothioate diesters do not react with maleimides in conditions that are suitable for the preparation of conjugates, or at least not to an extent detectable by the analysis techniques used in this study (HPLC and MALDI-TOF MS). Diene-derivatized PS-ONs successfully underwent Diels-Alder cycloadditions with maleimide-containing compounds, and reaction between maleimido-[PS-ONs] and thiol-containing compounds also provided the target conjugates.

An important point is that maleimide-[PS-ONs] can be synthesized using solid-phase methodologies, by incorporation of a [protected maleimido]-phosphoramidite building block to resin-linked PS-ONs. The [protected maleimido]-[PS-ONs] obtained after treatment with ammonia can be heated to remove the maleimide protecting group, and no maleimidephosphorothioate diester reaction was observed even in these relatively harsh conditions. The

maleimido-[PS-ONs] thus obtained were of the same purity as maleimido-[phosphodiestercontaining oligonucleotides].

Altogether, these results provide additional, strong support to the compatibility between thiophosphate diesters of PS-ONs and maleimides, and disagree with previous claims suggesting the contrary. They confirm that the most reactive sulfur nucleophile is the one that preferably gives the conjugate addition, and that phosphorothioate diesters do not interfere with the thiolmaleimide addition.

Finally, [thiophosphate monoester]-maleimide conjugation was also examined. On the one hand, it was found that 5 -thiophosphate- $\mathrm{dT}_{10}$ underwent dephosphorylation, which resulted in considerable loss of reagent. On the other, the yield of the conjugation reactions was lower than that of the other methods. Briefly, in our hands either Diels-Alder or maleimide-thiol 
conjugations gave better results than reaction between maleimides and oligonucleotides with a 5'thiophosphate monoester.

Supporting information. Synthesis and characterization of compounds $\mathbf{1}$ and $\mathbf{8 a}$, HPLC traces of compounds $3, \mathbf{6}, \mathbf{1 0}$ and $\mathbf{1 1}$, and preliminary experiments to assess thioester-maleimide reactivity. This material is free of charge via the Internet at http://pubs.acs.org.

\section{ACKNOWLEDGMENT}

This work was supported by funds from the Ministerio de Ciencia e Innovación (grant CTQ201021567-C02-01, and the project RNAREG, grant CSD2009-00080, funded under the programme CONSOLIDER INGENIO 2010), and the Generalitat de Catalunya (2009SGR-208). A. S. was a recipient fellow of the Generalitat de Catalunya.

\section{REFERENCES}

(1) Matsukura, M., Shinozuka, K., Zon, G., Mitsuya, H., Reitz, M., Cohen, J. S., and Broder, S. (1987) Phosphorothioate analogs of oligodeoxynucleotides: inhibitors of replication and cytopathic effects of human immunodeficiency virus. Proc. Natl. Acad.Sci. USA 84, 7706-7710. (2) Goodchild, J. (1990) Conjugates of oligonucleotides and modified oligonucleotides: A review of their synthesis and properties. Bioconjugate Chem. 1, 165-187.

(3) Diala, I., Osada, A., Maruoka, S., Imanisi, T., Murao, S., Ato, T., Ohba, H., and Fujii, M. (2007) Synthesis of phosphorothioate oligonucleotide-peptide conjugates by solid phase fragment condensation. Bioorg. Med. Chem. Lett. 17, 6575-6578.

(4) Goody, R. S., and Eckstein, F. (1971) Thiophosphate analogs of nucleoside di- and triphosphates. J. Am. Chem. Soc. 93, 6252-6257.

(5) Wettstein, P. J., Borson, N. D., Park, J. G., McNallan, K. T., and Reed, A. M. (2005)

Cysteine-tailed class I-binding peptides bind to $\mathrm{CpG}$ adjuvant and enhance primary CTL responses. J. Immunol. 205, 3681-3689. 
(6) Antopolsky, M., Azhayeva, E., Tengvall, U., Auriola, S., Jääskeläinen, I, Rönkkö, S., Honkakoski, P., Urtti, A., Lönnberg, H., and Azhayev, A. (1999) Peptide-oligonucleotide phosphorothioate conjugates with membrane translocation and nuclear localization properties. Bioconjugate Chem. 10, 598-606.

(7) Bongartz, J. P., Aubertin, A.-M., Milhaud, P. G., and Lebleu, B. (1994) Improved biological activity of antisense oligonucleotides conjugated to a fusogenic peptide. Nucleic Acids Res. 22, 4681-4688.

(8) Stetsenko, D. A., Arzumanov, A. A., Korshun, V. A., and Gait, M. J. (2000) Peptide conjugates of oligonucleotides as enhanced antisense agents. Mol. Biol. 34, 852-859.

(9) Gait M. J. (2003) Peptide-mediated cellular delivery of antisense oligonucleotides and their analogues. Cell Molec. Life Sci. 60, 844-853.

(10) Fidanza, J. A., and McLaughlin, L. W. (1989) Introduction of reporter groups at specific sites in DNA containing phosphorothioate diesters. J. Am. Chem. Soc. 111, 9117-9119.

(11) Gryaznov, S. M., and Letsinger, R. L. (1993) Chemical ligation of oligonucleotides in the presence and absence of a template. J. Am. Chem. Soc. 115, 3808-3809.

(12) Lee, J. H., Wong, N. Y., Tan, L. H., Wang, Z., and Lu, Y. (2010) Controlled alignment of multiple proteins and nanoparticles with nanometer resolution via backbone-modified phosphorothioate DNA and bifunctional linkers. J. Am. Chem. Soc. 132, 8906-8908. (13) Lee, P., and Colman, R. F. (2005) Adenosine 2'-monophosphate, 5'- $O$-[S-(4succinimidylbenzophenone)-thiophosphate]: a new photoaffinity label for the coenzyme site of porcine NADP-specific isocitrate dehydrogenase. Bioconjugate Chem. 16, 650-659.

(14) Karim, A. S., and Weltman, J. K. (1993) Formation of protein conjugates of phosphorothioate nucleoside diphosphate beta-S. Nucleic Acids Res. 21, 5281-5282 (15) Karim, A. S., Johansson, C. S., and Weltman, J. K. (1995) Maleimide-mediated protein conjugates of a nucleoside triphosphate gamma-S and an internucleotide phosphorothioate diester. Nucleic Acids Res. 23, 2037-2040.

(16) Ahn, D-R., Han, K-C., Kwon, H. S., and Yang, E. G. (2007) ATP-conjugated peptide inhibitors for calmodulin-dependent protein kinase II. Bioorg. Med. Chem. Lett. 17, 147-151. (17) Kaneda, M., Masuda, S., Tomohiro, T., and Hatanaka, Y. (2007) A simple and efficient photoaffinity method for proteomics of GTP-binding proteins. ChemBioChem 8, 595-598. 
(18) Kim, S. H., Jeong, J. H., Mok, H., Lee, S. H., Kim, S. W., and Park, T. G. (2007) Folate receptor targeted delivery of polyelectrolyte complex micelles prepared from ODN-PEG-folate conjugate and cationic lipids. Biotechnol. Prog. 23, 232-237.

(19) Alam, M. R., Dixit, V., Kang, H., Li, Z-B., Chen, X., Trejo, J., Fisher, M., and Juliano, R. L. (2008) Intracellular delivery of an anionic antisense oligonucleotide via receptor-mediated endocytosis. Nucleic Acids Res. 36, 2764-2776.

(20) Rabe, K. S., and Niemeyer, C. M. (2011) Selective covalent conjugation of phosphorothioate DNA oligonucleotides with streptavidin. Molecules 16, 6916-6926.

(21) Hussain, S., Plückthun, A., Allen, T. M., and Zangemeister-Wittke, U. (2006)

Chemosensitization of carcinoma cells using epithelial cell adhesion molecule-targeter liposomal antisense against bcl-2/bcl-xL. Mol. Cancer Ther. 5, 3170-3180.

(22) Sassolas, A., Leca-Bouvier, B. D., and Blum, L. J. (2008) DNA biosensors and microarrays. Chem. Rev. 108, 109-139.

(23) Williams, B. A. R.; Diehnelt, C. W.; Belcher, P.; Greving, M.; Woodbury, N. W.; Johnston, S. A.; Chaput, J. C. (2009) Creating Protein Affinity Reagents by Combining Peptide Ligands on Synthetic DNA Scaffolds. J. Am. Chem. Soc. 131, 17233-17241.

(24) Putta, M. R., Zhu, F-G., Wang, D-Q., Bhagat, L., Dai, M., Kandimalla, E. R., and Agrawal, S. (2010) Peptide conjugation at the 5'-end of oligodeoxynucleotides abrogates Toll-like receptor 9-mediated immune stimulatory activity. Bioconjugate Chem. 21, 39-45.

(25) Niemeyer, C. M. (2010) Semisynthetic DNA-protein conjugates for biosensing and nanofabrication. Angew. Chem. Int. Ed. 49, 1200-1216.

(26) Yanai, H., Chiba, S., Ban, T., Nakaima, Y., Onoe, T., Honda, K., Ohdan, H., and Taniguchi, T. (2011) Suppression of immune responses by nonimmunogenic oligodeoxynucleotides with high affinity for high-mobility group box proteins (HMGBs). Proc. Natl. Acad. Sci. USA 108, $11542-11547$.

(27) Sánchez, A., Pedroso, E., and Grandas, A. (2011) Maleimide-dimethylfuran exo adducts: Effective maleimide protection in the synthesis of oligonucleotide conjugates. Org. Lett. 13, 4364-4367.

(28) Iyer, R. P., Egan, W., Regan, J. B., and Beaucage, S. L. (1990) 3H-1,2-benzodithiole-3-one 1,1-dioxide as an improved sulfurizing reagent in the solid-phase synthesis of oligodeoxyribonucleoside phosphorothioates. J. Am. Chem. Soc. 112, 1253-1254. 
(29) Hill, K. W., Taunton-Rigby, J., Carter, J. D., Kropp, E., Vagle, K., Pieken, W., McGee, D. P., Husar, G. M., Leuck, M., Anziano, D. J. and Sebesta, D. P. (2001) Diels-Alder bioconjugation of diene-modified oligonucleotides. J. Org. Chem. 66, 5352-5358.

(30) Pulido, D., López-Alonso, J. P., Marchán, V., González, C., Grandas, A., and Laurents, D. V. (2008) Preparation of ribonuclease S domain-swapped dimers conjugated with DNA and PNA: Modulating the activity of ribonucleases. Bioconjugate Chem. 19, 263-270.

(31) Marchán, V., Ortega, S., Pulido, D., Pedroso, E., and Grandas, A. (2006) Diels-Alder cycloadditions in water for the straightforward preparation of peptide-oligonucleotide conjugates. Nucleic Acids Res. 34, e24.

(32) Ellman, G. L (1959) Tissue sulfhydryl groups. Arch. Biochem. Biophys. 82, 70-77.

(33) Ortega, S., Marchán, V., and Grandas, A. unpublished results.

(34) Lo Conte, M., Pacifico, S., Chambery, A., Marra, A., and Dondoni, A. (2010) Photoinduced addition of glycosyl thiols to alkynyl peptides: use of free-radical thiol-yne coupling for posttranslational double-glycosylation of peptides. J. Org. Chem. 75, 4644-4647.

(35) Ashley, G. W., and Kushlan, D. M. (1991) Chemical synthesis of oligodeoxynucleotide dumbbells. Biochemistry 30, 2927-2933. 


\section{FIGURES AND SCHEMES}

A)
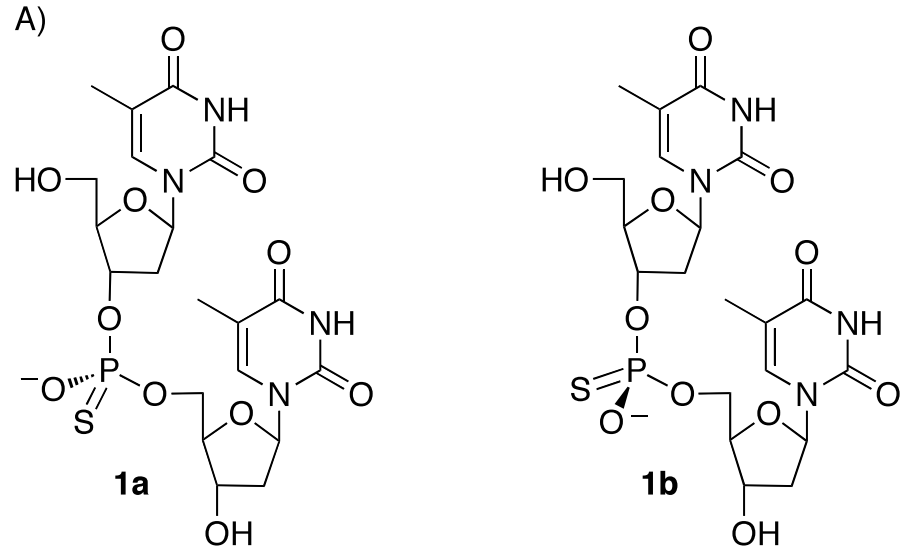

B)

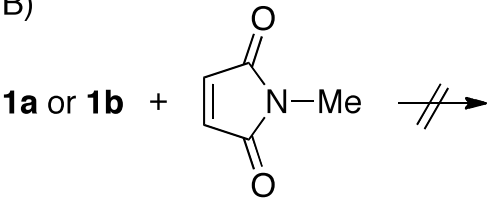

Figure 1. A) Structures of the two dT-PS-dT diastereomers (1a and 1b). B) Neither of these compounds reacted with $N$-methylmaleimide. 


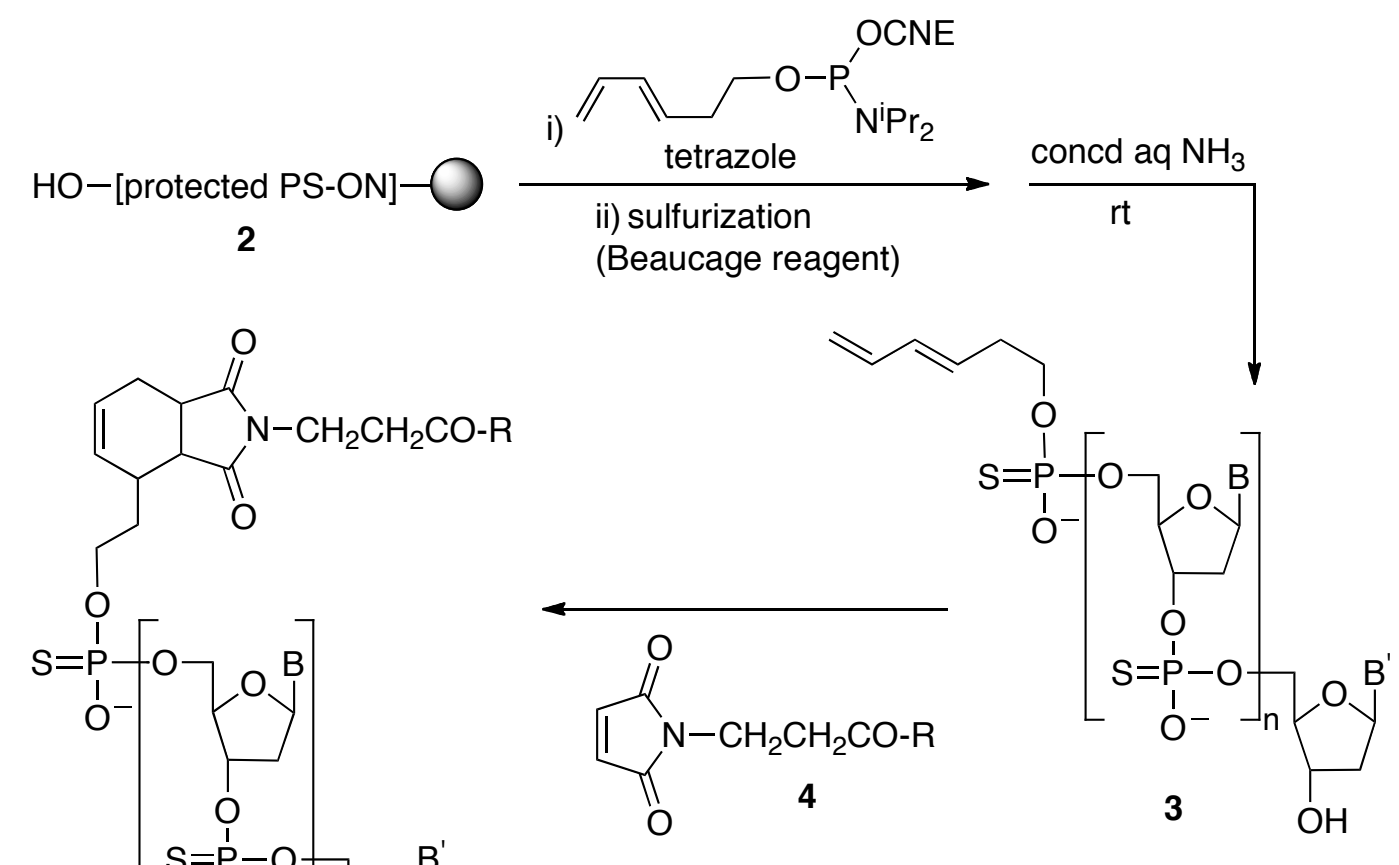

[PS-ONs] 2, 3 and 5:

$\mathrm{dT}_{10}(\mathbf{a}),{ }^{5} \mathrm{dTCTCCCAGCGTGCGCCAT}$ (b)

$\mathrm{R}:$

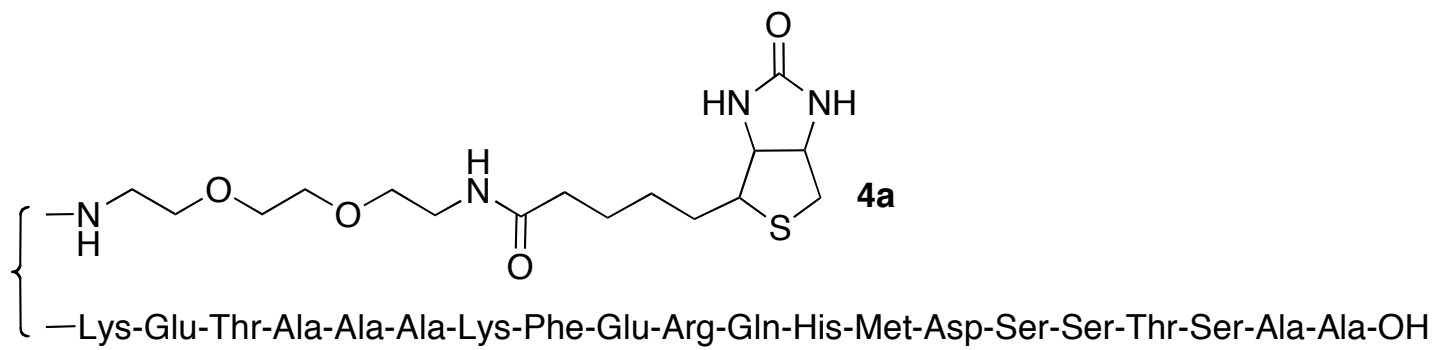

$4 b$

Scheme 1. Conjugation of diene-derivatized PS-ONs with maleimido-derivatized compounds making use of the Diels-Alder cycloaddition. 
a)

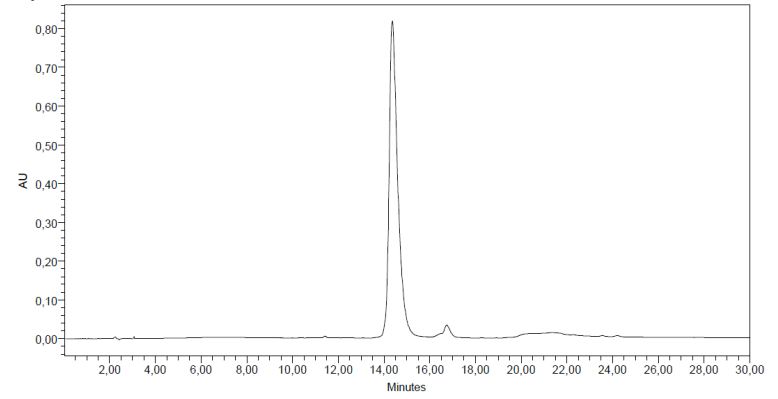

c)

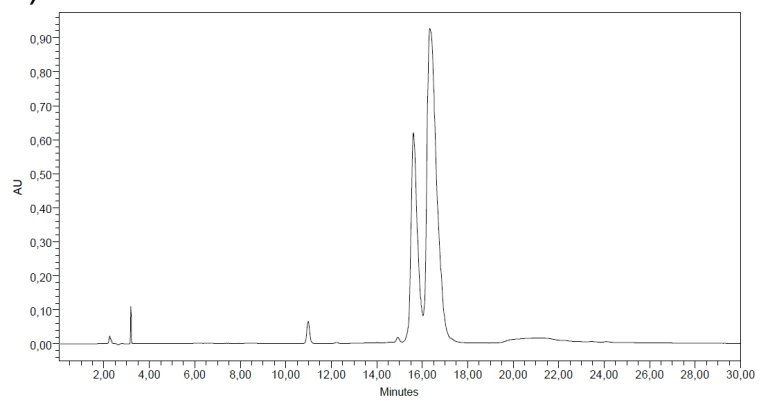

e)

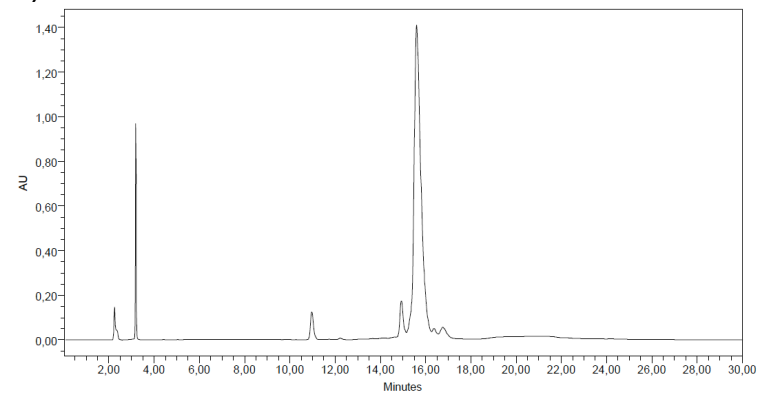

b)

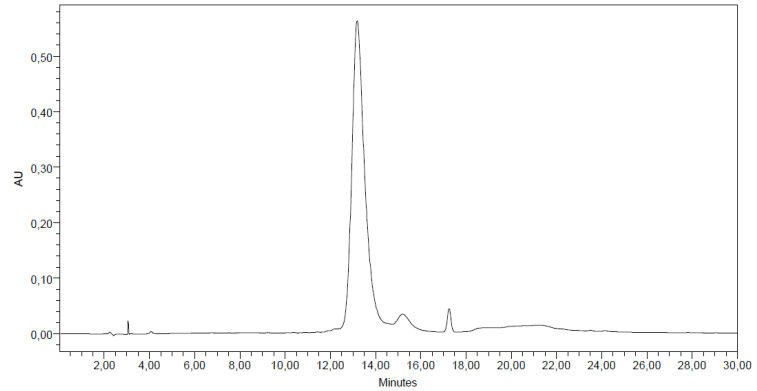

d)

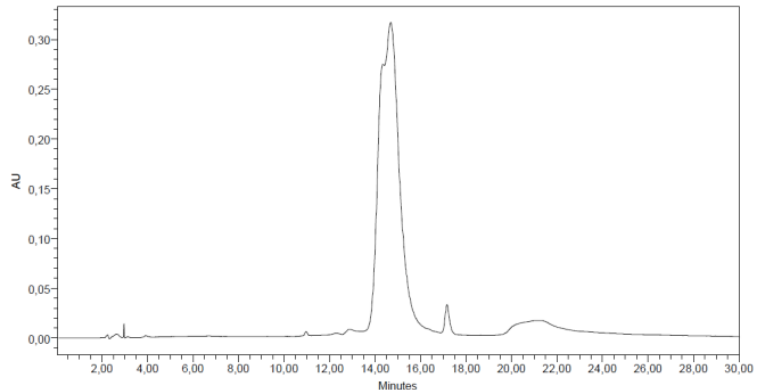

f)

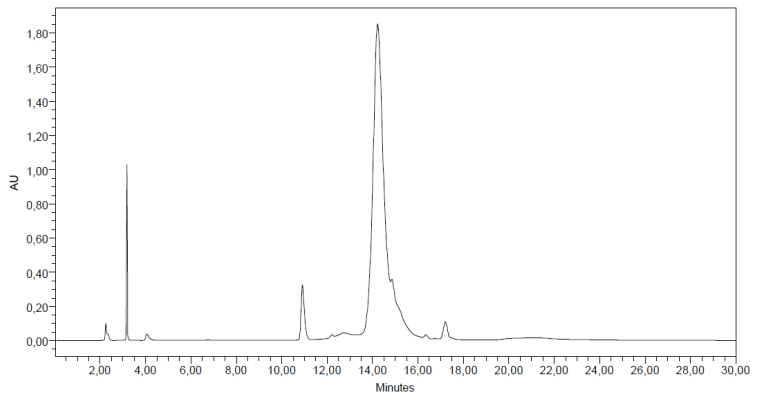

Figure 2. HPLC profiles of the Diels-Alder conjugation crudes. a) Diene- ${ }^{5}\left[\mathrm{PS}-\mathrm{dT}_{10}\right](\mathbf{3 a})+$ maleimido-peptide (4b), 1:2 molar ratio; $b$ ) diene-- ${ }^{5}$ [PS-dTCTCCCAGCGTGCGCCAT] (3b) + maleimido-peptide (4b), 1:2 molar ratio; $c$ ) diene-- ${ }^{5}\left[\mathrm{PS}-\mathrm{dT}_{10}\right](\mathbf{3 a})+$ maleimido-biotin (4a), 1:2 molar ratio; $d$ ) diene- ${ }^{5}$ [PS-dTCTCCCAGCGTGCGCCAT] (3b) + maleimido-biotin (4a), 1:2 molar ratio; e) 5'-diene-[PS-dT 10 (3a) + maleimido-biotin (4a), 1:12 molar ratio; $f$ ) diene- ${ }^{5}$ [PSdTCTCCCAGCGTGCGCCAT] (3b) + maleimido-biotin (4a), 1:12 molar ratio. 

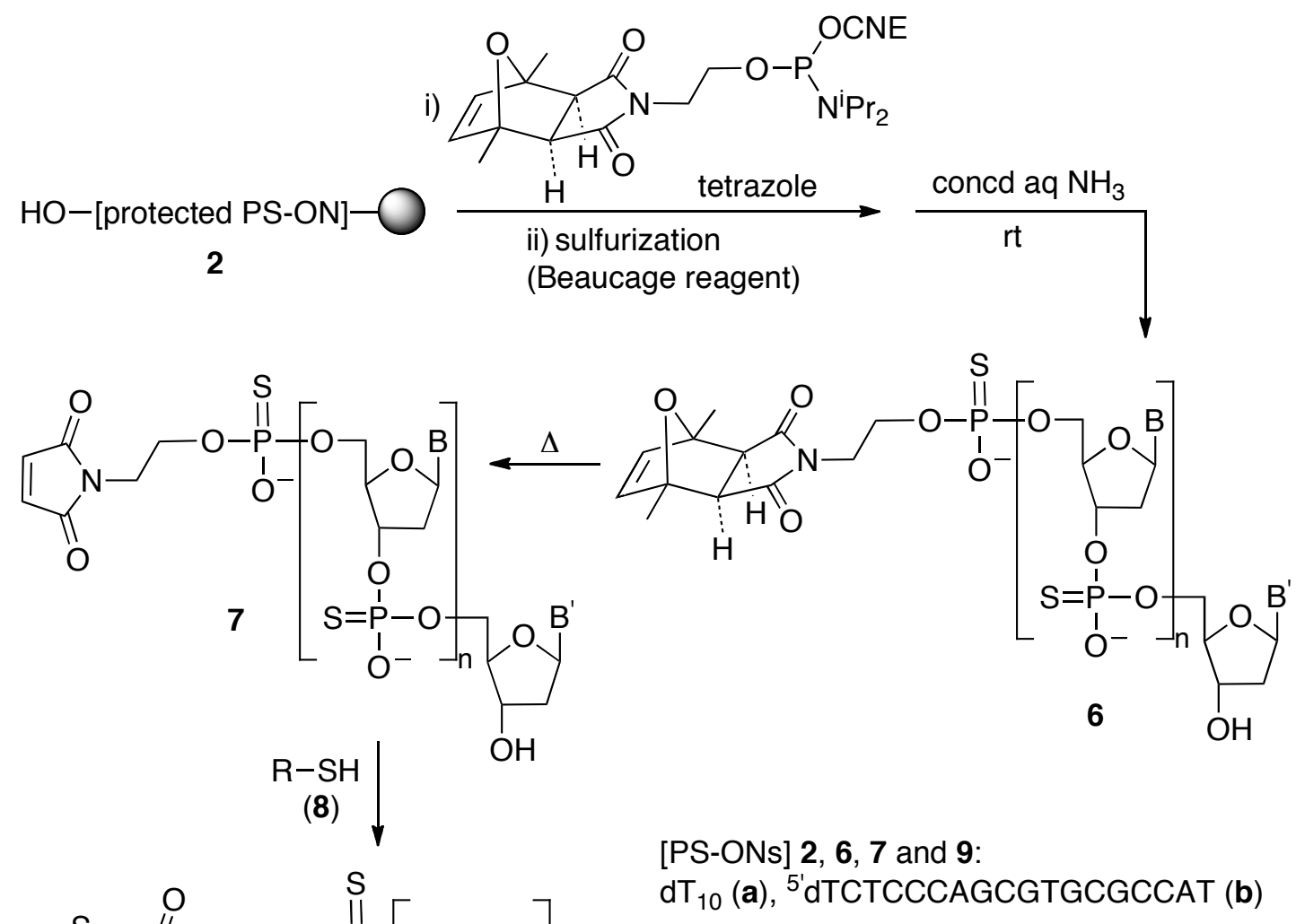

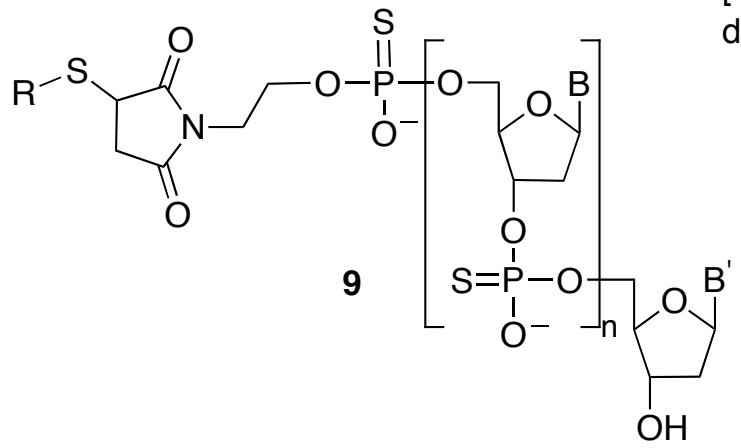

[PS-ONs] 2, 6, 7 and 9

(a), dTCTCCCAGCGTGCGCCAT (b)<smiles>NC(N)=O</smiles>

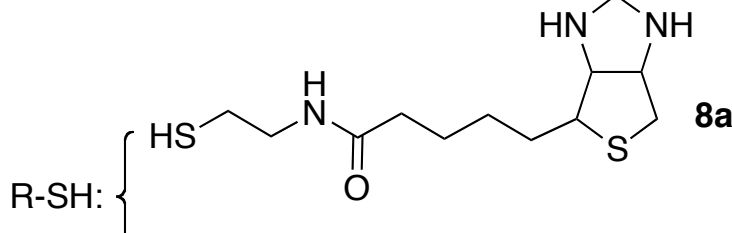

H-Cys-Lys-Glu-Thr-Ala-Ala-Ala-Lys-Phe-Glu-Arg-Gln-His-Met-Asp-Ser-Ser-Thr-Ser-Ala-Ala-OH

$8 b$

Scheme 2. Preparation of maleimido-derivatized [PS-ONs] (7), and conjugation with thiols (Michael-type reaction). 
a)

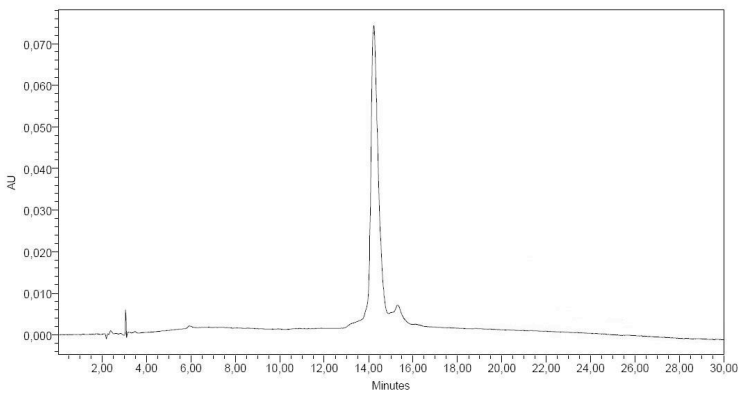

b)

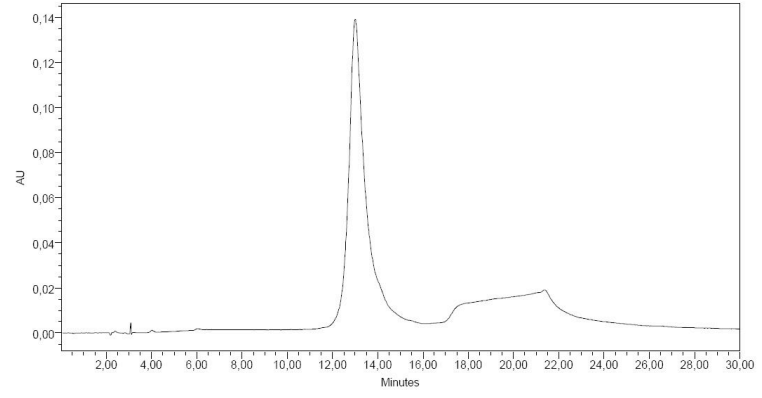

Figure 3. Crude maleimido-oligonucleotides (7) after heating in toluene (3 h, $\left.90{ }^{\circ} \mathrm{C}\right)$. a) Maleimido-- ${ }^{5}\left[\mathrm{PS}-\mathrm{dT}_{10}\right]$ (7a); $d$ ) maleimido-- ${ }^{5}[\mathrm{PS}-\mathrm{dTCTCCCAGCGTGCGCCAT]} \mathrm{(7b).}$ 
a)

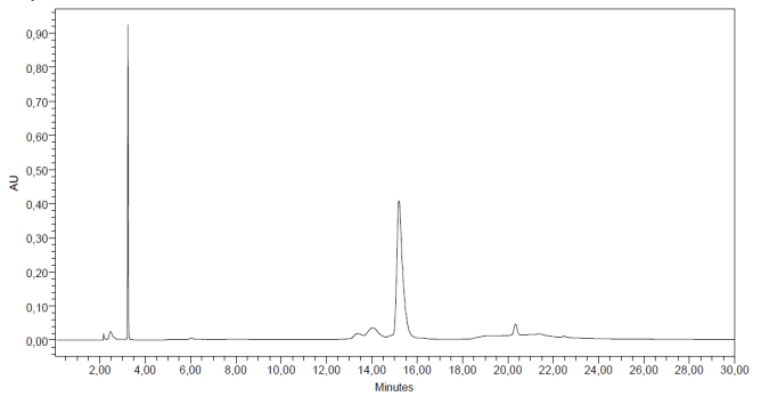

c)

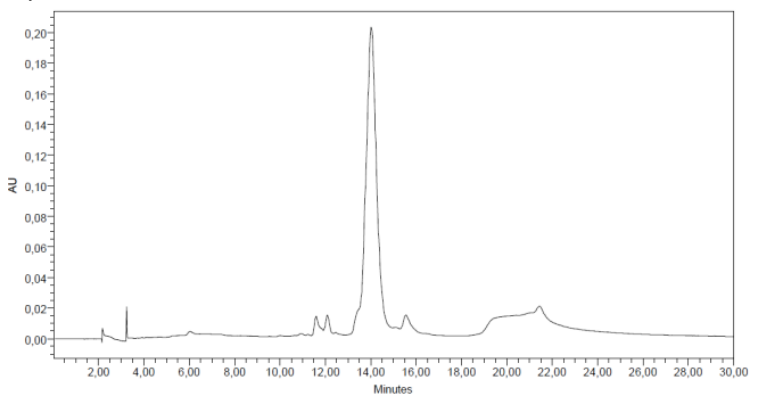

b)

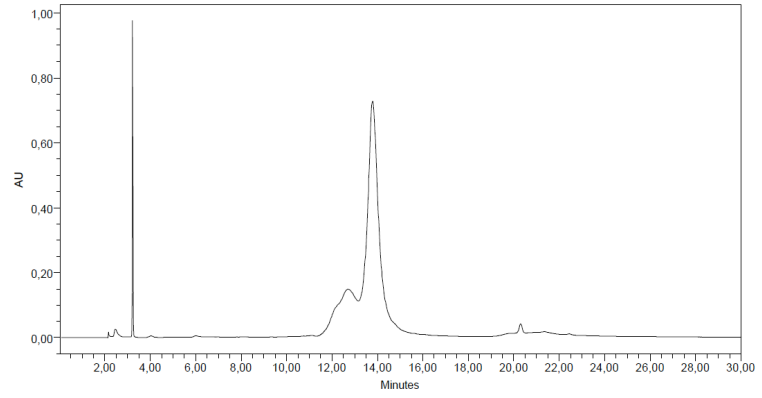

d)

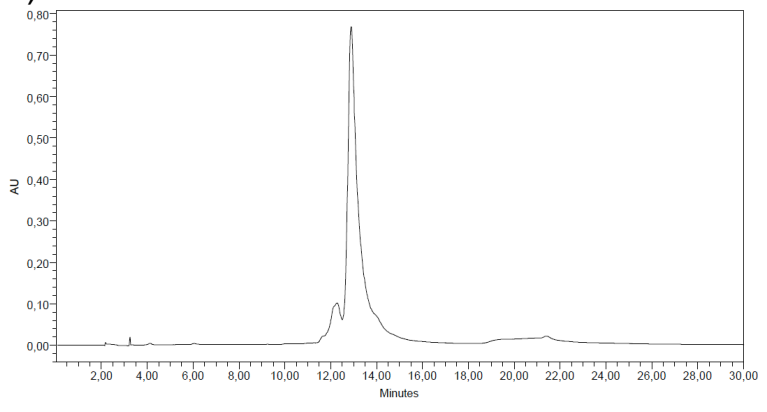

Figure 4. HPLC profiles of the thiol-maleimide conjugation crudes. $a$ ) Maleimido- ${ }^{5}\left[\mathrm{PS}-\mathrm{dT}_{10}\right]$ (7a) + HS-biotin (8a); b) maleimido-- ${ }^{5}$ PS-dTCTCCCAGCGTGCGCCAT] (7b) + HS-biotin (8a); c) maleimido- ${ }^{5}\left[\mathrm{PS}-\mathrm{dT}_{10}\right](\mathbf{7 a})+$ Cys-peptide $\left.(\mathbf{8 b}) ; d\right)$ maleimido- ${ }^{5}[\mathrm{PS}-$ dTCTCCCAGCGTGCGCCAT] (7b) + Cys-peptide (8b). 


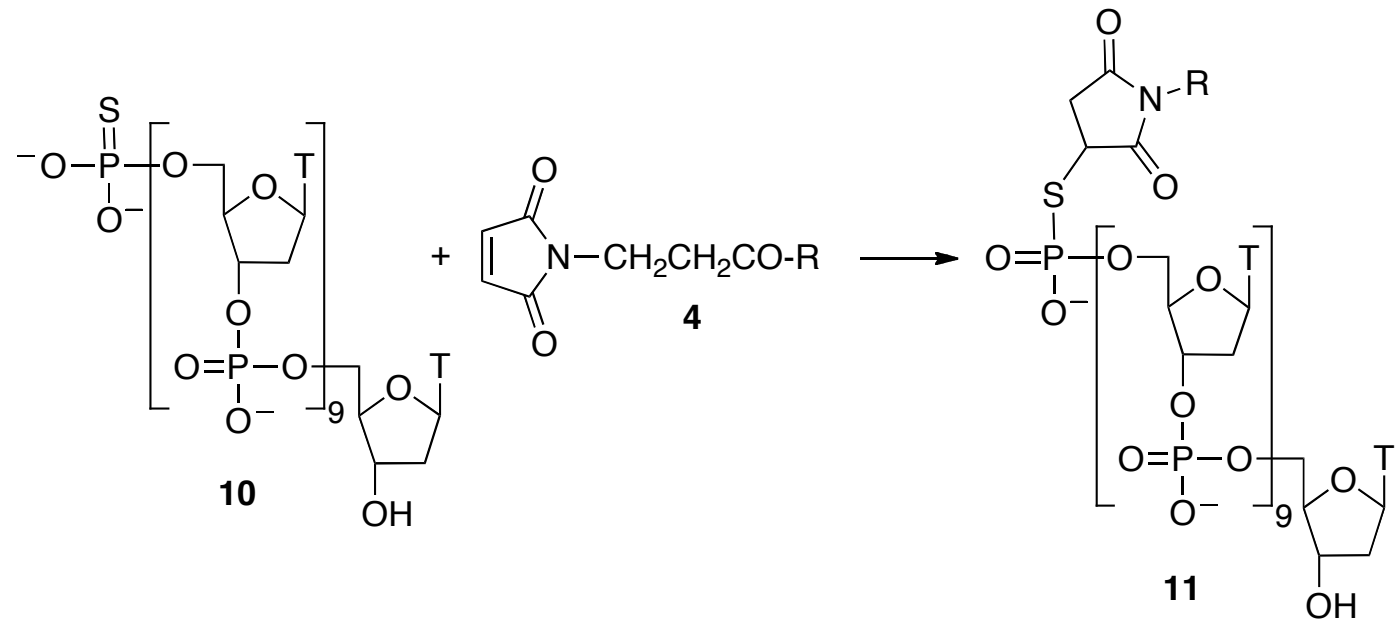

Scheme 3. Conjugation by reaction between 5'-phosphorothioate- $\left[\mathrm{dT}_{10}\right](\mathbf{1 0})$ and maleimidocompounds 4 (structures shown in Scheme 1). 
TOC graphic:

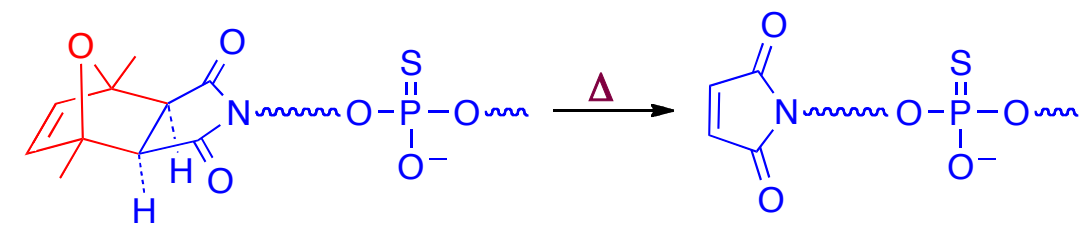
maleimido-PS oligonucleotide

No side reactions: thiophosphate diesters do not add to maleimides

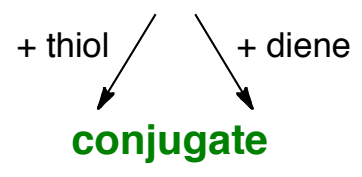

